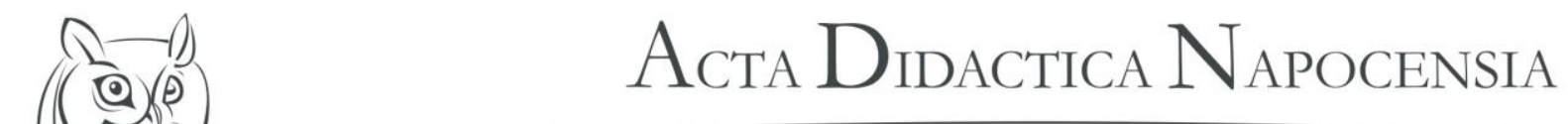

Volume 10, Number 2, 2017

\title{
Pre-Service Primary School Teachers' SPATIAL ABILITIES
}

\author{
Iuliana Marchis
}

\begin{abstract}
Spatial abilities are used in many aspects of everyday life, thus developing these abilities should be one of the most important goal of Mathematics Education. These abilities should be developed starting with early school years, thus pre-school and primary school teachers have an important role in setting the foundation of these abilities. A teacher can successfully develop students' competencies/abilities if she/he possess those competencies/abilities. Thus evaluating and developing pre-service primary school teachers' spatial abilities is an important goal of their training. This paper presents a research on pre-service primary school teachers' spatial abilities. Students were tested using an online problem sheet and the results were quantitatively and qualitatively evaluated, trying to identify some common misconceptions. The results show the necessity of developing these students' spatial abilities. Based on the results, some hands-on activities and paper based problem types are proposed for developing students' spatial abilities.
\end{abstract}

Keywords: Spatial ability, pre-service primary school teachers, Mathematics Education, teacher training

\section{Introduction}

Spatial ability is an important ability in our everyday life and in many careers. This ability is important in learning Geometry (Battista \& Clements, 1991; Capraro, 2001), but also there is a strong link between spatial ability and success in learning Mathematics (Grissmer, et al, 2010; Mix \& Cheng, 2012) or even in Sciences (Wai, Lubinski, \& Benbow, 2009; Newcombe, 2010). Spatial thinking is not only correlated with mathematical results, but also predicts the later mathematical performance (Cheng \& Mix 2013; Farmer, et al., 2013; Verdine, et al 2013). Researches show socioeconomic status related differences (Verdine, et al, 2013) and gender related differences (Lippa, Collaer, \& Peters, 2010) in spatial ability.

Developing pupils' geometrical competencies and spatial ability is not one of the main goals of primary school education (Uttal et al., 2012), usually there are only few hours per year spent on Geometry focusing mainly on geometrical notions, not on the development of abilities and competencies. Children come to preschool and primary school with an informal spatial ability (Bryant, 2008), but this usually is not formally supported until the end of the secondary school. In Romania pupils learn Spatial Geometry in $8^{\text {th }}$ grade, before in primary school and $5^{\text {th }}$ grade just learn about different geometrical solids on a level of notions, without trying to develop spatial skills. Therefor in $8^{\text {th }}$ grade many pupils have difficulties in seeing in space the figures which they make for solving Spatial Geometry problems. This also highlights the necessity of developing spatial ability starting with preschool in order to reach an adequate level for studying Spatial Geometry. For an effective formal development of this ability the teacher should possess high spatial ability level and methodological knowledge on how to develop this ability in students. Thus evaluating and developing pre-service primary school teachers' spatial abilities is an important goal of their training. 
The aim of this paper is to present the results of a research on pre-service primary school students' spatial ability.

\section{Theoretical background}

Spatial ability is a set of mental processes which are used in perceiving, storing, recalling, creating, arranging and making related spatial images (Linn \& Petersen, 1985), the ability to create mental images and to manipulate these images in mind (Battista \& Clements, 1998). The most important spatial skills are the following: the ability to visualize mental rotation of objects; the ability to understand how objects appear in different positions; the ability to conceptualize how objects relate to each other in space; the ability to understand objects in 3-D space (Sutton \& Williams, 2008). In the literature the terms spatial ability, spatial skills, visualization ability, visual-spatial ability are used interchangeably (Cantürk-Günhan et al., 2009). In this paper we will use the term "spatial ability".

For testing spatial ability there are some tests, as mental rotation test (Vanderberg \& Kuse, 1978), cube comparison test, paper folding test (Ekstrom, French, Hartman, 1976), hidden patterns test (French, Ekstrom, \& Price, 1962). In the mental rotation test a 3-dimensional image is given and some possible rotated correspondences, and participants have to choose that image which is the rotated correspondence of the given image. In case of the cube comparison test participants are asked if two cubes are identical or not (two cubes can be identical but seen from different angles, so one is obtained from the other by rotation). In case of the paper folding test a piece of paper is folded three times then there are some holes punched in it, then participants have to identify how the paper will look when unfolded. In case of the hidden pattern test participants have to determine if a given figure is embedded in a bigger figure (Silver, Tremaine \& Velez, 2006).

Physical manipulatives (Moyer, Bolyard \& Spikell, 2001) and digital technologies that allow visual and kinetic interactions (Clements \& Sarama, 2011; Sinclair \& Moss, 2012) help developing the spatial ability.

\section{Research}

The aim of this research is to study pre-service primary school students' spatial ability, mostly related with solving spatial problems dedicated for primary school pupils. The research was carried out in the 2014/2015 university year at Babes-Bolyai University from Cluj-Napoca (Romania).

\subsection{Participants}

73 Primary and Preschool Pedagogy specialization students from Babes-Bolyai University have participated in this research: $36.99 \%$ first year, $31.51 \%$ second year, and $31.51 \%$ third year students. $4.11 \%$ of the participants were male students and $95.89 \%$ female students. This high percentage of female students is usual for this specialization. As regarding the participants age, $71.23 \%$ were younger than 25 years, $28.77 \%$ between 25 and 45 years old, and $2.74 \%$ older than 45 years. Students' participation was voluntary.

\subsection{Data collection}

The research tool is a problem sheet with 7 problems (see the Appendix) and a short questionnaire with 3 demographical questions and 2 questions related with the felt difficulty level of the problems. Students were forced to give an answer for each problem, they didn't have the possibility to leave the solution blank, if they were unsure.

The given problems were selected mostly from problems dedicated for primary school pupils. Problem 4 was given International Mathematical Kangaroo Contest in 2000 for grades 3-4; Problem 5 was given at the final of the International Mathematical Competition "Zrínyi Ilona" in 2008 for grade 4; Problem 6 was given at the first level of the International Mathematical Competition "Zrínyi Ilona" in 2007 for grade 3 and 4; and Problem 7 was given at the final of the International Mathematical Competition "Zrínyi Ilona" in 2007 for grade 3. 
As the main goal was to see how pre-service primary school teachers solve spatial problems dedicated to primary school pupils, we didn't use a standardized test for studying students' spatial ability, we have chosen from different problems from textbooks or mathematical competitions instead.

\subsection{Results and discussion}

In Table 1 we summarize the percentages of students choosing each variant in case of each problem. The percentage for the correct variant is with bold.

Table 1. Percentages of students choosing different variants in case of each problem.

\begin{tabular}{lllllll}
\hline Problem & $\mathrm{A}(\%)$ & $\mathrm{B}(\%)$ & $\mathrm{C}(\%)$ & $\mathrm{D}(\%)$ & $\mathrm{E}(\%)$ & $\mathrm{F}(\%)$ \\
\hline 1 & 1.37 & 0 & $\mathbf{9 1 . 7 8}$ & 6.85 & & \\
2 & 12.33 & 12.33 & 34.25 & $\mathbf{3 9 . 7 3}$ & & \\
$3-$ value of $d$ & 5.48 & 26.03 & 13.70 & $\mathbf{5 0 . 6 8}$ & 1.37 & 2.74 \\
$\quad$ value of $e$ & 30.14 & $\mathbf{6 1 . 6 4}$ & 5.48 & 1.37 & 0 & 1.37 \\
$\quad$ value of $f$ & $\mathbf{5 8 . 9 0}$ & 4.11 & 6.85 & 26.03 & 1.37 & 2.74 \\
4 & 2.74 & $\mathbf{7 6 . 7 1}$ & 8.22 & 6.85 & & \\
5 & 28.77 & 0 & $\mathbf{1 7 . 8 1}$ & 28.77 & 19.18 & \\
6 & 13.70 & $\mathbf{3 8 . 3 6}$ & 19.18 & 16.44 & 12.33 & \\
7 & 12.33 & 2.74 & 8.22 & $\mathbf{6 7 . 1 2}$ & 8.22 & \\
\hline
\end{tabular}

In Problem 1 a cube with different patterns on its sides is given, and student have to choose its net from 4 possible nets. (See Appendix.). Most of the students (91.78\%) solved this problem correctly (Table 1). The difficulty level of this kind of problems very much depends on the images/shapes/numbers from the sides of the cube. In another research related with pre-school primary school teachers spatial reasoning there were three problems in which connections of a cube and its net occurred (Zsoldos-Marchis, 2015). The problem in which a cube was given and students have to find it's net from given possibilities (so similar with the problem in this research) was the easier for them, three quarters have solved it correctly. The other two problems was solved correctly by one third of the participants. In one problem a net was given and students have to find the cube which can be folded from it; in the other problem a cube was given and the students have to find the images of the cube from other orientation. To help students to cope better with this kind of problems, manipulatives could be used at the beginning and then gradually moving to mental folding or rotation. So students make the net given in the problem, fold it, then choose the right cube; or they make the cube given in the problem and rotate it to find its rotated image, etc.

In Problem 2 (see Appendix) a 3-dimensional construction is given and students have to choose the right view from above from 4 given possibilities. 39.73\% of the students solved it correctly. The students, who gave incorrect answer, didn't take in consideration the lines which can be seen from above (see Figure 1), and how the lines from the higher part of the object connects to the lines with the lower part of it.

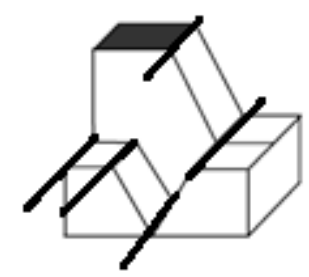

Figure 1. The lines which are guidelines when identifying the above view

In Problem 3 (see Appendix) a net of a regular dice is given with 3 missing numbers, and students have to find these numbers. For this they have to fold mentally the net into a cube in order to observe 
which side are opposite sides. (The sum of the numbers from the opposite side is 7.) $50.68 \%$ of the students found correctly the value of $d, 61.64 \%$ the value of $e$, and $58.90 \%$ the value of $f$. A high percentage $(26.03 \%)$ of the students gave the value 2 for $d$, these students considered $d$ being the opposite of side 5, but in fact these sides are adjacent. The same mistake appears in case of the value of $e$, where $30.14 \%$ of the students considered $e$ to be 1 , and in case of the value of $f$, where $26.03 \%$ of the students considered $f$ to be 4 . In case of this problem making the net given in the figure then folding it helps students visualizing which sides are opposite sides.

In Problem 4 (see Appendix) the views from 4 directions are given, and students have to find the 3 dimenstional construction which corresponds with these views. This problem was quite easy for students, $76.71 \%$ of them solved it correctly. This kind of problems are quite frequent in different mathematical tests or competitions. As a first step for helping students who can't cope with this kind of problems is to encourage them to build the object from cubes then observe it from different angles. A good learning material which can be used is Tridio® (Bakker, 2008).

Problem 5 (see Appendix) was given at the final of the International Mathematical Competition "Zrínyi Ilona" in 2008 for grade 4, where $5 \%$ of the pupils solved it correctly and $64 \%$ leave this solution blank (Csordás et al, 2009). It is a more difficult problem, where the solver have to roll mentally the dice and draw the dice in the new position. In our research $17.81 \%$ of the pre-service primary school teachers solved it correctly.

Problem 6 was given at the first level of the International Mathematical Competition "Zrínyi Ilona" in 2007 for grade 3 and 4 . This problem was solved correctly by $8 \%$ of the $3^{\text {rd }}$ grade pupils and $11 \%$ of the $4^{\text {th }}$ year students, and half of the pupils didn't give any answer (Csordás et al, 2008). As regarding pre-service primary school students, $38.36 \%$ of them solved it correctly. $13.70 \%$ have chosen variant (A), they didn't take into account the fact that "every two sides, on which the sum of the numbers are 9, are different color". $12.33 \%$ have chosen variant (E), they didn't take into account the fact that "the opposite sides are not the same color".

Problem 7 was given at the final of the International Mathematical Competition "Zrínyi Ilona" in 2007 for grade 3 . It was solved correctly by $52 \%$ of the $3^{\text {rd }}$ grade pupils. As regarding pre-service primary school teachers, $67.12 \%$ of them solved it correctly.

Analyzing students' answers related with the difficulty of spatial ability problems, $45.21 \%$ of them found them difficult, because "it was difficult to imagine in 3-simensions the figure drawn in 2dimensions", "it was difficult to imagine and rotate mentally the cube". Also, some of these students said that these kind of problems are unfamiliar for them. Part of those students, who didn't find these problems difficult, used manipulatives to solve the problems, as a dice or self-made manipulatives.

\section{Conclusions}

The average of the percentages of correct solution in case of each problem is $55.86 \%$, so we can say that in average about half of the students solved the spatial ability problems correctly. But the results differ very much from a problem to another one, the lowest success having Problem 5, with $17.81 \%$ of the students solving it correctly, and the highest success having Problem 1 with $91.78 \%$ of the students giving the correct answer. An important aspect to highlight is that most of the problems are selected from those given for primary school pupils at different competitions, so future primary school teachers should be able to solve this kind of spatial ability problems. The research results show the necessity of developing pre-service primary school teachers' spatial ability and the competence of solving different spatial problems.

Manipulatives help students to visualize the problems, and progressively they can switch from concrete folding/unfolding and rotation into mental operations. Also, using manipulatives with preservice primary school teachers help them to learn methodological tricks for developing their pupils' spatial ability. 


\section{References}

[1] Bakker, M. (2008). Spatial Ability in Primary School: Effects of the Tridio® Learning Material. Master Thesis of Psychology University of Twente, Enschede.

[2] Battista, M. \& Clements, D. (1991). Using spatial imagery in geometric reasoning. Arithmetic Teacher, 39, 18-21.

[3] Battista, M.T. \& Clements, D.H. (1998). Students' Spatial structuring of 2D arrays of Squares. Journal for Research in Mathematics Education, 29 (5) 503-532.

[4] Bryant, P. (2008). Paper 5: Understanding spaces and its representation in mathematics. In T. Nunez, P. Bryant, \& A. Watson (Eds.), Key understanding in mathematics learning: A report to the Nuffield Foundation.

[5] Cantürk-Günhan, B.; Turgut, M.; \& Y1lmaz, S. (2009). Spatial Ability of a Mathematics Teacher: The Case of Oya, IBSU Scientific Journal 3 (1), 151-158.

[6] Capraro, R. (2001). Exploring the influences of geometric spatial visualization, gender, and ethnicity on the acquisition of geometry content knowledge. Paper presented at the annual meeting of the Southwest Educational Research Association, New Orleans, LA.

[7] Cheng, Y. L., \& Mix, K. S. (2012). Spatial training improves children's mathematics ability. Journal of Cognition and Development. Advanced online publication.

[8] Clements, D. H., \& Sarama, J. (2011). Early childhood teacher education: The case of geometry. Journal of Mathematics Teacher Education, 14(2), 133-148.

[9] Csordás M.; Csordásné Szécsi J.; Csordás P.; Dobozi D.; Huszka T.; Nagy T.; Pap-Szigetiné Németh A.; \& Szabó I. (2008). Zrínyi 2007. A 2007. évi Zrínyi Ilona Matematikaverseny feladatai, megoldásai és eredményei. MATEGYE Alapítvány

[10] Csordás M.; Koleszár E.; Háriné Kun É.; Huszka T.; Nagy T.; \& Pap-Szigetiné Németh A. (2009). Zrínyi 2008. A 2008. évi Zrínyi Ilona Matematikaverseny feladatai, megoldásai és eredményei. MATEGYE Alapítvány

[11] Ekstrom, R. B., French, J. W., \& Harman, H. H. (1976). Manual for kit of factor-referenced cognitive tests. Princeton: Educational Testing Service.

[12] Farmer, G., Verdine, B.N., Lucca, K., Davies, T., Dempsey, R., Hirsh-Pasek, K., \& Golinkoff, R.M. (2013). Putting the pieces together: Spatial skills at age 3 predict to spatial and math performance at age 5. Poster presented at the 2013 Meeting of The Society for Research in Child Development Conference, Seattle, WA.

[13] French, J. W., Ekstrom, R. B., \& Price, L. A. (1962). A manual for Kit of Reference Tests for Cognitive Factors. Princeton, N. J.: Educational Testing Service.

[14] Linn, M.C. \& Petersen, A.C. (1985). Emergence and Characterization of Sex Differences in Spatial Ability: A-Meta Analysis. Child Development, vol. 56, 1479-1498.

[15] Lippa, R. A., Collaer, M. L., \& Peters, M. (2010). Sex Differences in Mental Rotation and Line Angle Judgment Are Positively Associated with Gender Equality and Economic Development across 53 Nations. Archaeology of Sex Behavior, 39, 990-997.

[16] Mix, K.S. \& Cheng, Y-L. (2012). The relation between space and math: Developmental and educational implications. Advances in Child Development and Behavior, 197-242.

[17] Moyer, P. S. (2001). Are we having fun yet? How teachers use manipulatives to teach mathematics. Educational Studies in Mathematics, 47(2), 175-197.

[18] Newcombe, N. (2010). Picture this: Increasing math and science learning by improving spatial thinking. American Educator, 34(2), 29-35. 
[19] Uttal, D. H.; Meadow, N. G.; Tipton, E.; Hand, L. L.; Alden, A. R.; Warren, C.; \& Newcombe, N. (2012). The malleability of spatial skills: A meta-analysis of training studies. Psychological Bulletin, 139(2), 352-402.

[20] Silver, D., Tremaine, T., \& Velez, M. C. (2005). Understanding visualization through spatial ability differences. The Center for Advanced Information Processing at The State University of New Jersey, 511-528.

[21] Sinclair, N. \& Moss, J. (2012). The more it changes, the more it becomes the same: The development of the routine of shape identification in dynamic geometry environments. International Journal of Education Research, 51\&52, 28-44.

[22] Sutton, K., \& Williams, A. (2008). Developing a discipline-based measure of visualization. UniServe Science Proceedings, 115-120.

[23] Széplaki Gy-né. (2008). Te is látod amit én látok? Térszemlélet fejlesztés, 5-12. évfolyam, II. rész, Educatio kht.

[24] Vandenberg, S., \& Kuse, A. (1978). Mental Rotation, a Group Test of Three-Dimensional Spatial Visualization. Perceptual and Motor Skills, 47, 599-604

[25] Verdine, B. N., Golinkoff, R., Hirsh-Pasek, K., Newcombe, N., Filipowocz, A. T., \& Chang, A. (2013). Deconstructing building bocks: Preschoolers' spatial assembly performance relates to early mathematics skills. Child Development.

[26] Wai, J., Lubinski, D., \& Benbow, C. P. (2009). Spatial ability for STEM domains: Aligning over fifty years of cumulative psychological knowledge solidifies its importance. Journal of Educational Psychology, 101, 817-835.

[27] Zsoldos-Marchis, I. (2015). Students' argumentation skills on spatial ability problems. Proceedings of the International Conference on Education "Knowledge - Learning Freedom" (“Tudás - Tanulás - Szabadság”), 235-240.

[28] *** Matlap - Ifjúsági Matematikai Lapok (Mathematical journal for school pupils edited in Cluj-Napoca, Romania), http://www.matlap.org/

\section{Author}

Iuliana Marchis, Babes-Bolyai University, Cluj-Napoca (Romania).

E-mail: iuliana.marchis@ubbcluj.ro

\section{Appendix}

Problem 1. Which net corresponds to the given cube? (Matlap, 2002/9)
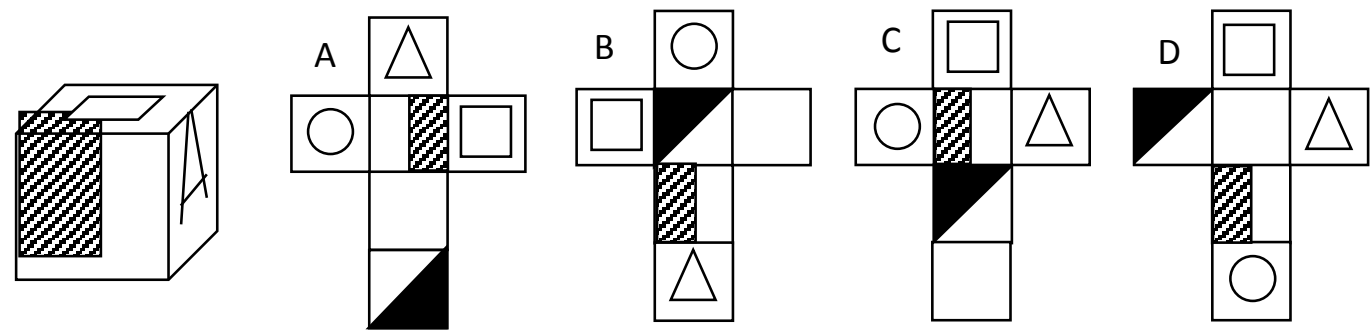

Problem 2. In the figure below we see a three-dimensional objects and it's possible views from above. Which one is the correct one? (Széplaki, 2008) 

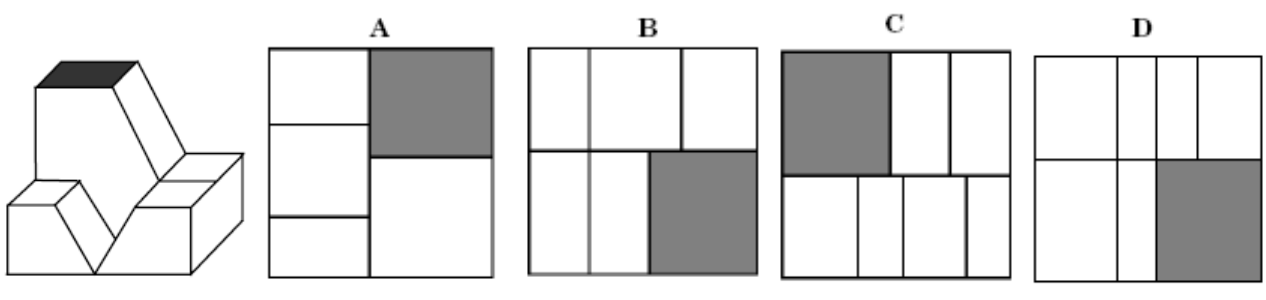

Problem 3. Knowing that in case of a dice the sum of the numbers from the opposite faces is 7 , find the values of $d, e$, and $f$ (Matlap, 2002/4)

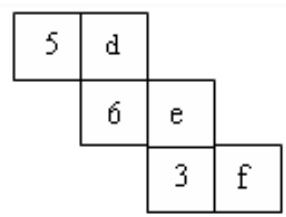

Problem 4. Which construction is shown as given from different directions? (Kangaroo Contest, 2000)

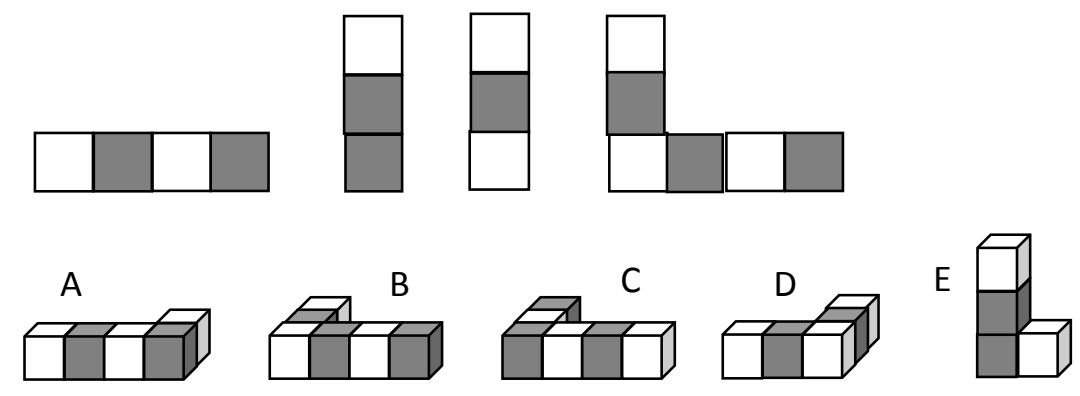

Problem 5. In the upper left side of a $3 \times 3$ square grid is a regular dice (see figure). In 4 steps the dice is rolled to the square marked with a star in all possible ways so that in each step the dice is rolled near an edge to the adjacent side. How many dots can't appear on the top side after the 4 steps?

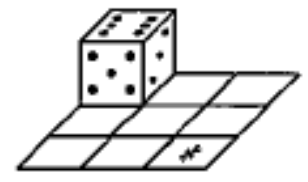
(A) 1
(B) 3
(C) 4
(D) 5
(E) 6
(Csordás et al, 2009)

Problem 6. Zoli painted the sides of a regular dice with red (R), yellow (S), and green (Z), using each color for exactly 2 sides. The opposite sides are not the same color; and every two sides, on which the sum of the numbers are 9, are different color. He painted with yellow the side with 1 dot and the opposite side of the 2 dot side; and he painted with red the opposite side of the 4 dot side. Then Zoli wrote the initials of the colors next to each other in the increasing order of the dots from the sides. What Zoli wrote?
(A) YGRGYR
(B) YRRGYG
(C) YRRYGG
(D) YYRGRG
(E) YGRRYG

(Csordás et al, 2008)

Problem 7. In the figure there is a $3 \mathrm{D}$ object build from 5 identical cubes. Which letter is on the opposite side with letter $\mathrm{C}$ ? 


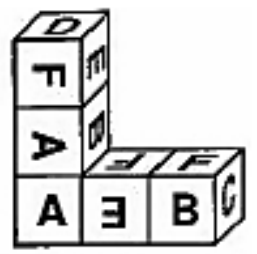
(A) $\mathrm{A}$
(B)
(C) $\mathrm{C}$
(D) $\mathrm{D}$
(E) E (F) F
(Csordás et al, 2009) 